\title{
Lyon 9e « Lugdunum »
}

Rue Joannès-Carret, quai Sédaillan

\section{Anne-Claude Rémy}

\section{(2) OpenEdition}

\section{Journals}

Édition électronique

URL : http://journals.openedition.org/adlfi/7033

ISSN : 2114-0502

Éditeur

Ministère de la culture

Référence électronique

Anne-Claude Rémy, "Lyon 9e « Lugdunum » », ADLFI. Archéologie de la France - Informations [En ligne], Rhône-Alpes, mis en ligne le 01 mars 2007, consulté le 22 avril 2019. URL : http:// journals.openedition.org/adlfi/7033

Ce document a été généré automatiquement le 22 avril 2019

(c) Ministère de la Culture et de la Communication, CNRS 


\title{
Lyon 9e « Lugdunum »
}

\author{
Rue Joannès-Carret, quai Sédaillan
}

\section{Anne-Claude Rémy}

\section{Identifiant de l'opération archéologique : 229680}

Date de l'opération : 2007 (EX)

1 Le site diagnostiqué entre les rues Carret et Sédaillan montre un substrat rocheux élevé sur la partie nord-est, sur lequel repose un banc de galets probablement tardiglaciaire, construit par la Saône. La rivière coulant sur le site à ce moment-là a déposé ce banc à la confluence de deux chenaux dans les périodes de crue. Le chenal secondaire venant du nord est alors rempli d'alluvions plus sableuses. Le retrait durable de la Saône laisse place à un plan d'eau se remplissant progressivement de craie, jusqu'à l'assèchement holocène permettant le développement d'un paléosol brun lessivé bien exprimé sur les points hauts. A proximité de la Saône, le retour de faibles crues intermittentes n'empêche pas une ou deux fréquentations protohistoriques (âge du Bronze ?) du lieu avant que des colluvions historiques et surtout les perturbations et remblaiements modernes à contemporains ne recouvrent tout le site.

Les niveaux anciens sont relativement bien circonscrits puisqu'ils se situent dans les sondages à proximité de la Saône. Ils se présentent sous la forme de sols contenant du mobilier céramique posé à plat. La particularité de cette découverte est que les artéfacts n'apparaissent pas au même niveau. Ils sont localisés soit au sommet, soit à la base de la couche. Ces différents éléments tendent à souligner le problème de la mise en place de ces couches (alluvions? colluvions?). Les très rares galets présents sur ce niveau ne permettent pas d'affirmer qu'il s'agisse d'une occupation intacte ou alors sous forme de lambeaux.

RÉMY Anne-Claude 
INDEX

Index géographique : Rhône-Alpes, Rhône (69), Lyon (69123)

Index chronologique : âge du Bronze, Protohistoire, Tardiglaciaire operation Expertise (EX)

\section{AUTEURS}

ANNE-CLAUDE RÉMY

INRAP 